\title{
Genomics and epidemiology for gastric adenocarcinomas
}

\author{
GE4GAC group
}

\begin{abstract}
Whereas the pathological aspects of Gastric Adenocarcinomas (GACs) have been well defined, the actual knowledge of its genesis and evolution remains to be translated to better diagnosis and to more effective therapeutics. As a consequence, the current treatment modalities are not yet able to modify the natural history of the disease, which still presents high mortality-rates worldwide. In this review we highlight the current status of relevant epidemiologic, therapeutic and genomics aspects of GACs and point to some of the current knowledge gaps that, if fully addressed, could contribute to a more effective treatment and better management of the patients that suffer from this often-lethal disease.
\end{abstract}

Keywords: Gastric Adenocarcinomas, Neoadjuvant Chemotherapy, Prognosis, Microbiome, Epidemiology, Genomics, Genetic admixture, Extracellular vesicles, Circulating tumor cells, Whole exome sequencing

\section{Background}

Gastric Cancer (GC) prevalence has shown a continuous reduction in the last 70 years, but is still a common malignancy and a frequent cause of cancer-related deaths worldwide [1-4]. The new-cases/mortality rate is much worse when compared to the more prevalent cancers: about $90 \%$ of the 800,000 people that are diagnosed with GC will die because of the disease [4-6]. In Brazil, after excluding the non-melanoma skin cancers, GC is the second more incident cancer type in men living in the North $(11.1: 100,000)$ and Northeast $(10.3: 100,000)$ regions [7].

GC mortality has been dropping around the globe, including Latin America, but the GC-related mortality rates still remain unacceptable in many areas [8-11]. Whereas in countries like the United Kingdom and USA the projected mortality rates for the year 2015 are below $5: 100,000$, it is above $10: 100,000$ in countries such as Brazil, Colombia, Japan and Korea and even higher (20:100,000) in Chile and the Russian Federation [11]. In Brazil, gastric cancer remains as a serious public health concern, especially in cities with high prevalence rates. An example is the city of Belém (North of Brazil, in Pará State) that shows disease prevalence above 20:100,000

\footnotetext{
* Correspondence: emmanuel@cipe.accamargo.org.br A.C.Camargo Cancer Center, Rua Prof. Antônio Prudente, 109, Liberdade, 01509-010 São Paulo, SP, Brazil
}

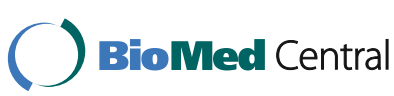

(c) The Author(s). 2016 Open Access This article is distributed under the terms of the Creative Commons Attribution 4.0 International License (http://creativecommons.org/licenses/by/4.0/), which permits unrestricted use, distribution, and reproduction in any medium, provided you give appropriate credit to the original author(s) and the source, provide a link to the Creative Commons license, and indicate if changes were made. The Creative Commons Public Domain Dedication waiver (http://creativecommons.org/publicdomain/zero/1.0/) applies to the data made available in this article, unless otherwise stated.
The most prevalent GC-subtype is the GAC, which comprises about $95 \%$ of the cases. GACs can be divided as intestinal, diffuse, mixed and non-classifiable subtypes [17]. Alternative GAC-classifications have been proposed, and since 2014 molecular classifications start being more widely adopted. Some articles suggested classifying GACs as Epstein-Barr virus positive tumors (EBV), lesions with microsatellite instability (MSI) and those presenting chromosomal instability (CIN) [18-21]. 
Table 1 Age distribution of new gastric cancer cases diagnosed in the USA between 2008 and 2012

\begin{tabular}{lc}
\hline Age at diagnosis & Percent \\
\hline$<20$ & 0.1 \\
$20-34$ & 1.7 \\
$35-44$ & 4.4 \\
$45-54$ & 12.3 \\
$55-64$ & 20.6 \\
$65-74$ & 25.2 \\
$75-84$ & 23.8 \\
$>84$ & 11.9 \\
\hline
\end{tabular}

(Source: SEER, 2016)

These classifications derived from large-scale genomic sequencing projects, which included hundreds of cases from distinct populations, providing a more solid molecular base for the disease classification.

Some of the current investigative projects include the evaluation of exogenous and endogenous elements in GAC development and progression, both very much related to epidemiologic aspects of the disease. Besides diet, tobacco and alcohol usage, exogenous elements include the classic Helicobacter pylori \& Epstein-Barr virus infections, as well as the more innovative study of the gastric microbiota and the role of drugs in GACdevelopment.

\section{The investigation of exogenous elements} Helicobacter pylori and the Epstein-Barr virus

The etiology of GCs and GACs results from a combined interaction of diverse causal mechanisms that include genetic susceptibility of the patient and exogenous elements, such as diet, tobacco and alcohol consumption, as well as the history of infection by certain microorganisms. As a general mechanism, it is believed that these elements act over the gastric mucosa leading to chronic inflammation, one of the first carcinogenic steps.

One of the most important causes of inflammation of the gastric mucosa is the infection by Helicobacter pylori $(\mathrm{Hp}) . \mathrm{Hp}$ is a gram-negative bacillus, present in about $50 \%$ of the world population [22]. Warren \& Marshall [23] were the first to suggest the GAC:Hp link, and this awarded them with the Nobel Prize of Medicine in 2005.

Table 2 Distribution of stomach cancer cases at diagnosis and 5-years survival rates for distinct stages of GC

\begin{tabular}{llc}
\hline & $\begin{array}{l}\text { Disease stage } \\
\text { at diagnosis (\%) }\end{array}$ & $\begin{array}{l}\text { 5-years } \\
\text { survival (\%) }\end{array}$ \\
\hline Localized disease & 26 & 65.4 \\
Lymph node disease & 29 & 29.9 \\
Metastatic disease & 35 & 4.5
\end{tabular}

Data derived from cases diagnosed and treated in the USA between 2005 and 2011. Source: SEER, 2016
The recognition that $\mathrm{Hp}$ can cause GAC led WHO to consider $\mathrm{Hp}$ as a carcinogenic agent [24] and to promote its eradication as one of the strategies to prevent the disease, even after tumor resection $[25,26]$.

Chronic gastritis, involving the activation of cellular and humoral responses in the gastric mucosa is one of the first signs of $\mathrm{Hp}$ infection [27]. $\mathrm{Hp}$ appears to be more prevalent in the Lauren's intestinal GAC subtype [28], which is characteristic of the CIN-TCGA classification [21]. When Hp evades this rich immunological response it leads to persistent infection and the chronic inflammation may evolve to a histologic progression first characterized as an unspecific chronic gastritis, with progressive gastric damage and atrophy of the mucosa. This is followed by the replacement of the normal glandular architecture by an intestinal-type metaplastic mucosa sometimes with the progressive development of cellular atypia (dysplasia), which culminate with GAC [29]. The virulence of the Hp-strain seems to correlate with the degree of this inflammatory process [30].

Another GAC-associated agent is the EBV herpesvirus (HHV-4), a double-stranded DNA virus with a 172,000 bases genome. EBV infection is also acquired by infants and when persistent may cause chronic gastric inflammation and cancer. Its oncogenic pathways involve the expression of membrane and viral nuclear antigens that interact with tumor suppressor genes and disturb many signaling pathways [31]. In Brazil, the EBV-associated GAC (GAC-EBV) has a prevalence of 4.7 to $12 \%$ [32-34] in agreement with the worldwide range of $\sim 7 \%$ [35]. The GAC-EBV is a unique clinicopathological entity: it appears to be more prevalent in men, is usually found in the proximal region of the stomach and is frequently present in younger subjects $[35,36]$. A recent publication found PIK3CA mutations in about $80 \%$ of GAC-EBV [20], and papers have reported that GAC-EBV patients usually have less lymph node disease but with contradictory prognosis reports [35-38].

\section{The gastric microbiota}

The human microbiota is the set of microorganisms that live in and on us. Recent estimates suggest that our microbiota is composed of $\sim 39$ trillion bacteria to about 30 trillion human cells, a roughly 1:1.3 ratio [39]. The microbiota can be perceived as an intermediate element between exogenous and endogenous factors, which helps metabolize diet components, acts as a physical barrier against the colonization by potentially pathogenic microorganisms and contributes to the development and maturation of our immune system [40-42].

A recent study of our group showed that the consumption of alcohol and tobacco severely reduces the number of bacterial species found in the oral mucosa [43]. Since these drugs appear to have a role in GACs, 
their impact in the microbiota has the potential to be important for disease development.

For a long period there was the belief that the stomach should be an essentially sterile cavity, a sort of acid barrier that would block the transfer and spread of microorganisms between the lower and the upper digestive tract [44]. However, as described above, the presence of $\mathrm{Hp}$ and EBV not only demonstrates the ability of some life forms to survive and to colonize the stomach, but also demonstrates a role of microorganisms in GAC development. In this context it is possible that other microorganisms could be also associated with GAC.

Up to now very few studies have focused on the analysis of the gastric microbiota in GACs. Stearns et al., 2011 [45] evaluated the oral, stomach, duodenum and the fecal microbiota of four individuals, using the sequencing of the V3-region of the 16S-rDNA bacterial gene. The result suggests a continuum in the microbiota along the gastrointestinal tract, with some microorganisms being restricted to particular organs. They also showed the stomach to have the lowest bacteria diversity among all body regions evaluated. A more recent study [46] evaluated the gastric microbiota in individuals diagnosed with non-atrophic gastritis, intestinal metaplasia, and intestinal-type gastric cancer. The findings of this study were limited by the low number of individuals $(n=$ 5/group) and the methods used (a small set of hybridization of probes), but suggested the microbiota diversity to be consistently reduced in GACs. More recently, the effects of subtotal gastrectomy on the microbiota present in the stomach tissue of six GAC patients were evaluated [47]. They found that bacterial diversity increased after surgery and that Ralstonia and Helicobacter decreased in abundance after tumor excision. However, their study was also limited by the number of individuals $(n=6)$ sampled. In a recent study [48], the gastric microbiota of four groups was analyzed; control $\mathrm{Hp}+(n=16)$, control Hp - $(n=13)$, cancer $\mathrm{Hp}+(n=15)$, cancer Hp $(n=19)$. No differences in diversity or phyla/genera abundances were observed between the groups, but the study had a major limitation: a shallow sequencing depth with an average of only 4,074 sequences/sample. In this sense, larger studies and more comprehensive approaches are needed to determine the role the microbiota plays in GACs.

\section{Diet, tobacco and alcohol}

Some authors showed that GAC-patients have a diet lacking complex carbohydrates, with high consumption of eggs, and low frequency of fresh fruits and vegetables [49-52]. The low consumption of fruits has been associated with the occurrence of pre-neoplastic lesions and higher GAC and the use of sodium chloride as a foodpreservative has been found to be positively associated with the disease [49-50]. As suggested [51], diets that are rich in antioxidants, such as $\beta$-carotene and ascorbic acid, appear to help reducing the incidence of GACs.

Tobacco use is an important risk factor for GACs [53, 54]. A possible correlation of GAC and alcohol-consumption also appears to exist, since frequent alcohol consumption leads to chronic gastritis, considered as one of the first gastric carcinogenesis steps [51]. A meta-analysis review [55] detected a $20 \%$ increment in the incidence of GACs in individuals that drink above four alcohol-doses/day.

\section{Studies of endogenous elements}

Ethnic aspects \& genomic ancestry

The incidence of GACs is high in the Middle East and in countries such as Brazil, Peru, Japan, the Koreas and China and the Russian Federation [56]. However, the GAC-related mortality varies in these regions, and it is not a simple reflex of economic discrepancies among these countries. Interestingly, the GAC-associated mortality for Japanese-descendants in Brazil is lower than that observed in Japan, but still $50 \%$ higher than that seen in Brazilians with no Japanese ancestry [57, 58]. Ethnic aspects also appear to play a major role in disease prognosis and response to treatment. The overall 5-year survival rate among Japanese patients, considering all clinical stages, is of $40-60 \%$, a sharp difference comparing to only $15-30 \%$ in the USA and Europe [59, 60]. At first sight this could be associated to an early diagnosis in a cultural milieu more alert to this neoplasia, or to better or more aggressive surgical approaches performed in Japan [61]. However, studies with Japanesedescendants living out of Japan indicate that ethnic issues play a major role. Taking into account the elevated ethnic admixture of some populations, including Brazilians, the precise determination of ancestry is important for future studies of GAC predisposition and prognosis.

A recent study evaluated 13,084 GAC patients diagnosed between 1988 and 2006, registered in Los Angeles, US and categorized as white (39\%), Hispanic (28\%), Asians (22\%), African-Americans (11\%) and others (2\%). The study found a much superior overall survival for Asians (16.3 months), when compared to the other groups (8.7-7.9 months, $p<0,001)$ [62]. As this study was done in the United States, it contradicts the hypothesis that Asian patients have a better outcome mainly due to distinct surgical treatment compared to Western patients.

The response to certain antineoplastic agents and targeted therapies also diverge between patients of different geographic-regions/ethnic background. As an example, the AVAGAST study, that evaluated the role of an antiangiogenic monoclonal antibody (bevacizumab) plus chemotherapy in the treatment of metastatic GC, found different responses between Asians and US patients [62]. 
In this study, whereas bevacizumab treatment gave no survival increment for Asians (13.9 months for patients treated with chemotherapy + bevacizumab $\times 12.1$ months for those treated with chemotherapy + placebo; HR 0.97 IC 95\% 0.75-1.25) it was more effective for US patients (11.5 months for chemotherapy + bevacizumab $\times 6.5$ months for chemotherapy + placebo; HR 0.63 IC 95\% 0.43-0.94). Unfortunately, survival rates for both US groups were worse than for Asians, emphasizing that ethnic/ancestry issues are relevant for predicting tumor behavior and treatment response [62].

\section{Genetic and genomics aspects}

Whereas most cases of GAC occur after 55 years of age, data from SEER, 2016 [16] shows that a small fraction (6.2\%) of the USA patients present the disease before age 45 (Table 1). The biological and clinicopathological features of the Early Onset GAC (EOGAC) are remarkably distinct from the sporadic GAC of older patients, suggesting these to be distinct entities $[63,64]$.

While endogenous factors such as germline mutations appear to impact the EOGAC more severely, exogenous factors are probably more relevant for the sporadic disease. After observing the occurrence of germline Ecadherin mutations $(C D H 1)$ in hereditary diffuse GAC, and the earlier onset of these tumors, groups start investigating this mutation in EOGAC. Kim et al. found only 2/25 EOGAC-patients to carry $C D H 1$-mutaions patients (<50 years-old) [63], and Corso et al., 2011 [65] obtained similar data $(2 / 21)$ for diffuse GACs. After reviewing the literature these authors found $7.2 \%$ of EOGAC carrying CDH1 mutations, but only $2.3 \%$ of EOGAC appear to have mutations that are highly likely to be pathogenic, and those were found in patients diagnosed before the age of 35 [66].

Diffuse hereditary GACs have particular clinical aspects, and patients carrying these tumors have been frequently identified with $\mathrm{CDH} 1$ mutations or promotermethylation [67-70]. Whereas the non-symptomatic individuals carrying $C D H 1$ mutations present a high risk of developing a diffuse-type GAC throughout life, endoscopic screening is usually not useful for early screening since the stomach has a normal appearance, and biopsies often fail to demonstrate malignancy. Therefore, preventive gastrectomy has been frequently suggested [71].

In Brazil, GAC is the most frequent non-colonic tumor type identified in the patients harboring the hereditary nonpolyposis colorectal cancer (HNPCC) syndrome and hereditary colorectal cancer [72, 73]. GAC is also present in a number of other syndromes including: - Hereditary Breast and Ovary Cancer (HBOC), related to BRCA1 and BRCA2 mutations; -Familial Adenomatous Polyposis (FAP); - Peutz-Jeghers Syndrome (associated with germline STK11 mutations);
- Juvenile Polyposis Syndrome, associated to SMAD4 and BMPR1A mutations; - Li-Fraumeni Syndrome (LFS), characterized by germline mutations of the TP53 gene.

\section{The most relevant molecular alterations identified in GACs}

GAC is a disease with a complex pattern of mutational, structural, karyotypic, as well as gene and protein expression. Besides this, chromosomal and DNA microsatellite instability have been frequently demonstrated in these tumors $[74,75]$.

Alterations in gene-expression patterns in the different carcinogenic steps of epithelial cell transition, going from inflammation to invasive neoplasia, have been recently investigated by large-scale next-generation RNA sequencing (RNA-Seq) and allowed the definition of gene signatures for distinct histological grades and histological types of GACs [21].

Holbrook et al. evaluated a gene panel composed of 384 genes frequently mutated in cancer, in an attempt to provide faster clinical applications in precision medicine and found frequent alterations in genes of the WNT pathway, tyrosine receptor kinases, as well as genes encoding proteins related to cell-cycle, DNA-repair and epithelial-mesenchymal-transition. From this data, the authors estimated that therapies already approved, or currently under development, may benefit $22 \%$ of the GACs that carry mutations in the target genes of these drugs [76].

In 2014, The Cancer Genome Atlas (TCGA) consortium published the study of 295 pairs of tumor $\mathrm{x}$ non-tumor gastric samples. This consortium employed six distinct analysis platforms - including mRNA \& miRNA expression studies, DNA methylation, copy-number variation and whole exome sequencing - in an attempt to define a consistent molecular classification of GAC [21]. The results suggest the existence of 4 major tumor-types: $\mathrm{EBV}^{+}$ (26/295), $\mathrm{MSI}^{+}$(64/295), GS (Genomically Stable, 58/295) and CIN (147/295). EBV ${ }^{+}$tumors showed high frequency of PIK3CA mutations (80\%) and were usually more frequently located in the fundus or gastric body $(62 \%, p=$ 0.02); $\mathrm{MSI}^{+}$tumors frequently occur in patients of more advanced age $\left(>72\right.$ years-old, $\left.p=5 \times 10^{-5}\right)$, an opposite trend to that seen for GS tumors (59 years-old, $p=4 \times 10$ ${ }^{-7}$ ). Also, $\mathrm{MSI}^{+}$tumors showed a higher frequency among diffuse-type tumors $\left(40 / 55=73 \%, p=8 \times 10^{-7}\right)$. RNA-Seq data found 4 mRNAs- and 5 miRNA-sets capable of distinguishing these molecular GAC-subtypes, and revealed new splicing isoforms of the MET gene, which showed to be associated with a higher expression of this proto-oncogene.

In this same year, Kakiuchi et al. performed WES of 30 diffuse-type GAC samples. Their findings pointed to an elevated frequency of $R H O A$-mutations that apparently 
lead to a gain-of-fuction of the encoded protein, which is a member of the RHO-GTPases family. The data was confirmed in a second set of samples and indicates that $25 \%$ of the diffuse GACs carry these mutations and may benefit of a new therapeutic approach [20]. This study also showed that, in most cases, the relatively common mutations found in RHOA and HER2, appear to be mutually exclusive. This suggests that RHOA could be a relevant target for patients that have no HER2 amplification [20].

In another recent publication, the whole genome sequencing (WGS) of 100 pairs of normal/tumor gastric tissue samples as well as studies of CNV, global methylation and RNA-Seq were reported. The finding of recurrent mutations in RHOA was confirmed and showed to be restricted to GACs of the diffuse-type (14.3\%). Driver-genes were identified for all the major GACsubtypes, and validated in independent cohorts. Genes relevant for GAC-biology were confirmed, including TP53, ARID1A and RHOA, and new driver genes were also identified (MUC6, CTNNA2, GLI3, RNF43 and others) [19].

When taken together, this recent literature shows that molecular classifications could be useful tools for the study of GACs, with direct applicability for cancer diagnosis for the search of new therapeutic targets. However, as these studies involved a relatively small number of tumors of few population groups - only Europeans, North-Americans and Asians - it is not possible yet to claim that the full GAC mutational-spectrum has been fully covered. The molecular profiles identified up to now were not confirmed in highly admixed populations, such as the Brazilian, and it is certain that the inclusion of genetically admixed individuals may reveal new molecular markers - a consequence of our genetic complexity [77].

\section{Molecular mechanisms associated with tumor progression and treatment resistance: identification of biomarkers \\ Treatment response and disease outcomes in GACs}

Even neoplasms with the same histological subtype, grade, stage and treatment have heterogeneous clinical outcome, thus suggesting that individual susceptibility must be searched in molecular grounds.

Perioperative chemotherapy associated with surgery is one of the main strategies in the treatment of stage II and III GAC patients. In this context, the addition of some cycles of chemotherapy before and after surgery reduces the risk of tumor relapse and death $[78,79]$. However, chemotherapy response is heterogeneous and so far there are no standard methods to assess it. The complete absence of viable cells in resected stomach and lymph nodes is a clear signal of response to chemotherapy and correlates positively with survival - unfortunately, this full response is only seen in less than $10 \%$ of the patients [80]. Thus, the identification of new markers of response to neoadjuvant chemotherapy may help to improve treatment decisions and outcomes in patients with potentially curable disease.

The treatment of patients with metastatic or relapsed GAC is another huge challenge. Surgery and radiotherapy have limited indication in this scenario and patients usually receive systemic treatment with platins, fluoropyrimidines, taxanes and topoisomerase inhibitors. In 2010 trastuzumab was the first target-specific therapy associated with a survival benefit in advanced gastric cancer patients [81]. It was incorporated in clinical practice as part of first-line regimen in combination with chemotherapy, but it's benefit is restricted to 20\% of cases that are positive for the amplification of ERBB2/ HER2 [82]. Ramucirumab is an anti-VEGFR2 monoclonal antibody that inhibits VEGF signaling and angiogenesis. In 2014, two randomized trials demonstrated the activity of ramucirumab in second line, either as monotherapy or associated with paclitaxel [83, 84]. More recently, a double-blind randomized study evaluated the activity of apatinib (another VEGFR2-inhibitor) in 267 heavily pretreated patients with advanced GACs. The study reported a modest but statistically significant improvement in progression free survival and overall survival in apatinib treated patients compared to placebo [85]. Taken together, these trials demonstrate that antiangiogenic drugs could be relevant in the treatment of advanced gastric cancer.

Recent publications suggest that new immunotherapeutic strategies may be promising opportunities for GAC patients. A recent study found the expression of PD-L1 in $51 \%$ of 132 samples of gastric cancer tumor, derived from Chinese patients. Whereas these authors found no relationship between PD-L1 expression and many clinicopathological variables (including age, gender, clinical stage, location and histological differentiation), PD-L1 positive patients had significantly poorer 5-years survival rates than negative patients $(51 \% \times 83.1 \%$ respectively, $P<$ 0.001) [86]. Preliminary clinical data from a phase I trial with the anti-PD1 antibody pembrolizumab revealed an overall response rate of $22 \%$ and a median duration of response of 6 months in a chemotherapy refractory population of GAC patients [87].

At this moment, all agents used in the management of metastatic GAC patients bring a perspective of temporary disease control but not cure, and the median survival is still below 1 year. They all have one point of convergence: resistance. Understanding the molecular events that drive the disease may help to identify the best responders to each agent (including immunotherapy) and to use resources and drugs more efficiently. 


\section{Circulating Tumor Cells (CTCs)}

Tumor dissemination requires the presence of cells that leave the primary site and circulates in blood. The capability of these cells to form tumors has been demonstrated and the number of CTCs per mL of blood has prognostic value [88]. It is known today that CTCs have 'organ-preferences' allowing a selective colonization process compatible with the historic concept of "seed and soil", first suggested by Stephen Paget in 1889 .

If we consider that the tumors - and the CTCs that they originate from - are immunologically distinct of the nontumor tissues, the requirement to escape the host's immune response is a constant pressure. One of the possible escape mechanisms is the establishment of groups of 'small tumors' or micro-emboli: aggregates of 5-10 cells that travel together in the blood, reach distant organs and promotes the recruiting of pro-angiogenic factors and the expression of new surface markers [89]. It is estimated that these CTC-clusters represent only about $\sim 3 \%$ of the total CTCs found in the blood. However, it has recently demonstrated that they are responsible for the formation of more then $50 \%$ of the metastasis [90], making their presence a major element in invasive metastatic tumors $[90,91]$. Therefore, it is possible that the study of CTCs could contribute more to the definition of anti-metastatic therapies than the study of the primary tumors.

Few studies, involving small patient groups, have evaluated the detection and the qualitative analysis of CTCs in GACs. Using the CellSearch ${ }^{\circ}$ system authors reported the detection of CTCs in $14 \%$ of patients with non-metastatic GACs and in $55 \%$ of patients with metastatic disease $(\geq 2$ CTCs/7.5 mL of blood) [92]. In agreement with studies of other tumors, elevated concentrations of CTCs ( $\geq 4$ CTCs/ $7.5 \mathrm{~mL}$ of blood) during treatment (2 to 4 weeks after the start of chemotherapy) were associated with worst prognosis of GACs (average survival of $3.5 \times 11.7$ months). CTCs also appear to impact chemotherapy response. A group in Japan studied 52 patients with advanced GAC and found an inverted relation between CTC-levels and the efficacy of distinct chemotherapeutic regimens [93]. Two recent metanalyses involving CTCs and the presence of specific circulating miRNAs suggest that patients positive for both had reduced disease-free survival, as well as a reduced overall survival $[94,95]$.

\section{Extracellular Vesicles (EVs)}

Extracellular Vesicles (EVs) are structures derived from cell membranes, secreted by many cell types, and carry a cargo of proteins, mRNAs, microRNAs, other non-coding RNAs and apparently some DNA [96]. EVs are an example of a well-organized system of cell-cell communication in physiologic and pathologic conditions [97].

Many studies have suggested that EVs are capable of transferring molecular information from the tumor microenvironment to distant sites, which confers them a pivotal role during tumor progression $[98,99]$. The most studied groups of EVs are the microvesicles, formed through the outward blabbing of the plasma membrane (average size ranging from 0.1 to $1 \mu \mathrm{m}$ ) and the exosomes, smaller vesicles (30 to $150 \mathrm{~nm}$ ) formed by the endosome pathway and released after the fusion of multi-vesicular bodies with the cell membrane [100].

Proteins and lipids present in the surface of EVs allow them to recognize certain molecules in the membrane of the target cells, thereby providing a very efficient signaling mechanism, and allowing the release of the EV's content that seem to trigger biological alterations in the receptor cell [101]. Our group has recently shown, using an in vitro model of breast cells, that the overexpression of only HER2 (which is also very important in GACs) induces dramatic proteome alterations in the EVs. Importantly, we found that EVs carry a heavy load of HER2 and are thus potentially able to disseminate this oncogene to other tissues and cells [102]. This is relevant in a scenario of tumor heterogeneity, where the amplification of HER2 is far from being homogeneous [82, 103], and can possibly impact the efficacy of Traztuzumab-treatment, as EVs may act as sponges sequestering the drug and reducing its tumor-availability. This finding may be relevant here, due to the use of traztuzumab in GACpatients with advanced disease, as previously mentioned.

The signals induced after the release of EVs in the body fluids of cancer patients can be related to a series of relevant aspects of tumor progression, including cell adhesion and survival, proliferation, invasion, inflammation, modulation of immune response, thrombosis and angiogesis [104]. Recent studies have shown that EVs have a key role in the development of the pre-metastatic niche, by promoting a communication between tumor and non-tumor cells and creating a favorable microenvironment adequate to the arrival and survival of circulating cancer cells in this new environment [98].

The roles of the EVs in GAC have been little studied. It is known that EVs secreted by gastric cancer cell lines promote the activation of the PI3K-AKT pathway and induce cell proliferation [105]. Li et al., 2014 recently suggested exosomes might serve as a protective structure, preserving useful biomarkers, such as long noncoding RNAs [106]. The quantitative analysis of EVs in the blood of GAC-patients showed these vesicles to be more concentrated in patients with more advanced GAC, and the increment of the proteins HER2/neu, MAGE-1, cMET e EMMPRIN, when compared to controls [104]. Since EVs carry molecular signatures of the tumors, the systematic mapping of these molecules and their target cells/tissues, can potentially contribute for the identification of biomarkers and drug targets in cancer. 


\section{Conclusions}

Gastric adenocarcinoma remains as a very important and challenging health issue in the world. Whereas its incidence curve showed a descendent slope in more developed nations, declining from 3 to $5 \%$ per year, it remained stable in the last 15 years with no recent trends of further reductions. In the underdeveloped nations of SouthAmerica and Asia this reduction had a slower pace of only about $1 \%$ per year. It should be noted that the mortality reduction achieved today derives more from earlier diagnosis than from the development of new therapeutic approaches or from advances in our knowledge of the molecular basis of the disease. Therefore, whereas the epidemiology of GACs must be continuously revisited and updated, the need for new therapeutic targets still lingers. Better diagnostic and prognostic markers are needed, and will help define disease-subgroups and pave the way to a deeper knowledge of the disease.

\section{Abbreviations}

GACs: Gastric adenocarcinomas; GC: Gastric cancer

\section{Acknowledgements}

GE4GAC network members are:

Fernando Augusto Soares', Felipe J. F. Coimbra², Adriane G. Pelosof ${ }^{3}$, Helano C Freitas ${ }^{4,5}$, Maria Dirlei Begnami ${ }^{1}$, Wilson Luis da Costa Jr. ${ }^{2}$, Marcello F. Fannelli ${ }^{4}$, Celso Abdon Lopes de Mello ${ }^{4}$, Maria Galli de Amorim ${ }^{5}$, Melissa Poll Pizzi $^{5}$, Luiza Caramelo ${ }^{5}$, Elisa N Ferreira ${ }^{6}$, Bruna DF Barros ${ }^{6}$, Giovana T. Torrezan ${ }^{6}$, Rodrigo Ramalho ${ }^{6}$, Dirce M Carraro ${ }^{6}$, Thiago Chulam, Fernanda Sulian de Carvalho ${ }^{7}$, Daniel D. De Carvalho ${ }^{8,9}$, Ana CV Krepischi ${ }^{10}$, Eduardo Tarazona-Santos ${ }^{11}$, Luiz Gonzaga Vaz Coelho ${ }^{12}$, Rosane Oliveira de Sant'Ana ${ }^{13}$ Rommel Rodríguez Burbano ${ }^{14}$, Paulo Assumpção ${ }^{15}$, João Carlos Setúbal ${ }^{16}$, Andrew M. Thomas ${ }^{5,16}$, Ludmilla TD Chinen ${ }^{17}$, Alexcia Camila Braun ${ }^{17}$, Vanessa Alves ${ }^{17}$, Edson K. Cassinela ${ }^{18}$, Gabriela Pintar de Oliveira ${ }^{18}$, Michele C. Landemberger $^{18}$, Renan Valieris ${ }^{19}$, Rodrigo Drummond ${ }^{19}$, Israel Tojal da Silva $^{19}$, Rodolfo Cézar ${ }^{20}$, Vinícius F. Calsavara ${ }^{20}$, Kalebe R. Nóbrega ${ }^{20}$, Irina G. Bobrovnitchaia ${ }^{19}$, Thais F. Bartelli ${ }^{5}$, Graziela PB Baladão ${ }^{20}$, Ana CC Pereira ${ }^{20}$, Camila M Gatti ${ }^{20}$, Lais Lie Senda de Abrantes ${ }^{17}$, Vilma Regina Martins ${ }^{18}$, Diana Noronha Nunes ${ }^{5}$, Maria Paula Curado ${ }^{20}$, Emmanuel Dias-Neto ${ }^{5}$ Department of Pathology ${ }^{1}$, Department of Abdominal Surgery ${ }^{2}$, Service of Endoscopy ${ }^{3}$, Department of Clinical Oncology ${ }^{4}$, Laboratory of Medical Genomics ${ }^{5}$, Laboratory of Genomics and Molecular Biology ${ }^{6}$, Department of Cancer Prevention ${ }^{7}$, International Research Center ${ }^{17}$, Cellular and Molecular Biology group ${ }^{18}$, Bioinformatics group ${ }^{19}$, Epidemiology group ${ }^{20}$, A.C.Camargo Cancer Center, São Paulo, SP, Brazil. Princess Margaret Cancer Centre ${ }^{8}$ University Health Network, Toronto, ON M5G 2 M9, Canada; Department of Medical Biophysics ${ }^{9}$, University of Toronto, Toronto, ON M5G 2 M9, Canada. Department of Genetics and Evolutionary Biology ${ }^{10}$, Institute of Biosciences, University of São Paulo, São Paulo, SP, Brazil. Laboratory of Human Molecular Diversity ${ }^{11}$, Institute of Biological Sciences and Hospital das Clínicas da Faculdade de Medicina ${ }^{12}$, Universidade Federal de Minas Gerais, Belo Horizonte, MG, Brazil. Department of Clinical Oncology, Instituto do Cancer do Ceará \& Universidade de Fortaleza ${ }^{13}$, Fortaleza, CE, Brazil. Laboratory of Molecular Biology, Hospital Ophir Loyola ${ }^{14}$ and Núcleo de Pesquisas em Oncologia ${ }^{15}$, Belém, PA, Brazil. Computational Biology and Genomics Research Center ${ }^{16}$, Department of Biochemistry, Institute of Chemistry, University of São Paulo, SP, Brazil.

ACVK, DMC, ED-N, ETS and VRM are research fellows of Conselho Nacional de Desenvolvimento Científico e Tecnológico (CNPq).

\section{Funding}

Fundação de Amparo à Pesquisa do Estado de São Paulo (FAPESP - project 2014/26897-0). This agency played no role in the study design, data collection and analysis, interpretation of the findings or manuscript writing.
Availability of data and materials

Not applicable.

\section{Authors' contributions}

The GE4GAC network contributed to the study design and manuscript writing.

\section{Competing interests}

The authors declare that they have no competing interests.

\section{Consent for publication}

Not applicable.

Ethics approval and consent to participate

Not applicable.

Received: 21 July 2016 Accepted: 6 September 2016

Published online: 10 March 2017

\section{References}

1. Ferlay J, Soerjomataram I, Ervik M, Dikshit R, Eser S, Mathers C, et al. Cancer Incidence and Mortality Worldwide: IARC CancerBase No. 11. GLOBOCAN v1.0 Lyon, France; 2012.

2. Parkin DM, Pisani P, Ferlay J. Estimates of the worldwide incidence of eighteen major cancers in. Int J Cancer. 1985;1993:594-606.

3. Nagini S. Carcinoma of the stomach: A review of epidemiology, pathogenesis, molecular genetics and chemoprevention. World J Gastrointest Oncol. 2012;4:156-69.

4. Bertuccio P, Chatenoud L, Levi F, Praud D, Ferlay J, Negri E, et al. Recent patterns in gastric cancer: a global overview. Int J Cancer. 2009;125:666-73.

5. Ferlay J, Shin HR, Bray F, Forman D, Mathers C, Parkin DM. Estimates of worldwide burden of cancer in 2008: GLOBOCAN 2008. Int J Cancer. 2010; 127:2893-917.

6. Matsuda A, Machii R. Trends in stomach cancer mortality rates in Japan, USA, UK, France and Korea based on the WHO mortality database. Jpn J Clin Oncol. 2012;42:154.

7. Latorre MR. Stomach cancer mortality in Brazil: from 1977 to 1989. Cad Saude Pub. 1997;13:67-78.

8. Bosetti C, Malvezzi M, Chatenoud L, Negri E, Levi F, La Vecchia C. Trends in cancer mortality in the Americas, 1970-2000. Ann Oncol. 2006;16:489-511.

9. Dikshit R, Gupta PC, Ramasundarahettige C, Gajalakshmi V, Aleksandrowicz $L$, Badwe R, et al. Cancer mortality in India: a nationally representative survey. Lancet. 2012;379:1807-16.

10. Bosetti C, Rodríguez T, Chatenoud L, Bertuccio P, Levi F, Negri E, et al. Trends in cancer mortality in Mexico, 1981-2007. Eur J Prev Cancer. 2011;20: 355.

11. Ferro A, Peleteiro B, Malvezzic M, Bosetti C, Bertuccio P, Levi F, et al. Worldwide trends in gastric cancer mortality (1980-2011), with predictions to 2015, and incidence by subtype. Eur J Cancer. 2014;50:1330-44.

12. Chatenoud L, Bertuccio P, Bosetti C, Levi F, Curado MP, Malvezzi M, et al. Trends in cancer mortality in Brazil, 1980-2004. Eur J Cancer Prev. 2010;19:79-86.

13. Silva GA, Gamarra CJ, Girianelli VR, Valente JG. Cancer mortality trends in Brazilian state capitals and other municipalities between 1980 and 2006. Cad Saude Pub. 2011;45:1009-18.

14. Bustamante-Teixeira MT, Faerstein E, Mariotto A, de Britto AV, Moreira Filho DC, Latorre MR. Survival in gastric cancer patients in Campinas, São Paulo, Brazil. Cad Saude Pub. 2006;22:1611-8.

15. Resende AL, Mattos IE, Koifman S. Gastric cancer mortality in the State of Pará, Brazil, 1980-1997. Arq Gastroenterol. 2006;43:247-51.

16. SEER Cancer Statistics Factsheets: Stomach Cancer. National Cancer Institute. Bethesda, MD, http://seer.cancer.gov/statfacts/html/stomach.html. Accessed in 21 Apr 2016.

17. Lauren P. The two histological main types of gastric carcinoma: diffuse and so-called intestinal type carcinoma: an atempt at a histo-clinical classification. Acta Pathol Microbiol Scand. 1965;64:31-49.

18. Wong SS, Kim KM, Ting JC, Yu K, Fu J, Liu S, et al. Genomic landscape and genetic heterogeneity in gastric adenocarcinoma revealed by wholegenome sequencing. Nat Commun. 2014:5:5477.

19. Wang K, Yuen ST, XU J, Lee SP, Yan HH, Shi ST, et al. Whole-genome sequencing and comprehensive molecular profiling identify new driver mutations in gastric cancer. Nat Genet. 2014;46:573-82. 
20. Kakiuchi M, Nishizawa T, Ueda H, Gotoh K, Tanaka A, Hayashi A, et al. Recurrent gain-of-function mutations of RHOA in diffuse-type gastric carcinoma. Nat Genet. 2014;46:583-7.

21. TCGA. Comprehensive molecular characterization of gastric adenocarcinoma. Nature. 2014;513:202-9.

22. Parsonnet J, et al. Helicobacter pylori infection and the risk of gastric carcinoma. N Engl J Med. 1991;325:1127-31.

23. Warren JR, Marshall B. Unidentified curved bacilli on gastric epithelium in active chronic gastritis. Lancet. 1983;1:1273-5.

24. IARC, IARC Monographs on the Carcinogenic Risks to Humans. Schistosomes, liver flukes and Helicobacter pylori. IARC Working Group on the Evaluation of Carcinogenic Risks to Humans. Lyon, 7-14 June 1994. IARC Monogr Eval Carcinog Risks Hum. 1994;61:1-241.

25. Roesler BM, Costa SCB, Zeitune JMR. Eradication Treatment of Helicobacter pylori Infection: Its Importance and Possible Relationship in Preventing the Development of Gastric Cancer. ISRN Gastroenterol. 2012;2012:935410.

26. Fukase $K$, Kato M, Kikuchi S, Inoue K, Uemura N, Okamoto S, et al. Effect of eradication of Helicobacter pylori on incidence of metachronous gastric carcinoma after endoscopic resection of early gastric cancer: an open-label, randomised controlled trial. Lancet. 2008;372:392-7.

27. Amedei A, Della Bella C, Silvestri E, Prisco D, D'Elios MM. T cells in gastric cancer: friends or foes. Clin Dev Immunol. 2012;2012:690571.

28. Parsonnet J, Vandersteen D, Goates J, Sibley RK, Pritkin J, Chang Y. Helicobacter pylori infection in intestinal and dissude-type gastric adenocarcinomas. J Natl Cancer Inst. 1991;83:640-3.

29. Polk DB, Peek RM. Helicobacter pylori: gastric cancer and beyond. Nat Rev Cancer. 2010;10:403-14.

30. Ashour AA, Magalhães PP, Mendes EN, Collares GB, Gusmão VR, Queiroz DM, et al. Distribution of vacA genotypes in Helicobacter pylori strains isolated from Brazilian adult patients with gastritis, duodenal ulcer or gastric carcinoma. FEMS Immunol Med Microbiol. 2002;33:173-8.

31. Young LS, Rickinson AB. Epstein-Barr virus: 40 years on. Nat Rev Cancer. 2004;4:757-68.

32. Begnami MD, Montagnini AL, Vettore AL, Nonogaki S, Brait M, Simoes-Sato AY, et al. Differential expression of apoptosis related proteins and nitric oxide synthases in Epstein Barr associated gastric carcinomas. World J Gastroenterol. 2006;12:4959-65.

33. de Souza CR, de Oliveira KS, Ferraz JJ, Leal MF, Calcagno DQ, Seabra AD, et al. Occurrence of Helicobacter pylori and Epstein-Barr virus infection in endoscopic and gastric cancer patients from Northern Brazil. BMC Gastroenterol. 2014;14:179.

34. Koriyama C, Akiba S, Iriya K, Yamaguti T, Hamada GS, Itoh T, et al. EpsteinBarr virus-associated gastric carcinoma in Japanese Brazilians and nonJapanese Brazilians in São Paulo. Jpn J Cancer Res. 2001;92:911-7.

35. Murphy G, Pfeiffer R, Camargo MC, Rabkin CS. Meta-analysis shows that prevalence of Epstein-Barr virus-positive gastric cancer differs based on sex and anatomic location. Gastroenterol. 2009;137:824-33.

36. Chen JN, He D, Tang F, Shao CK. Epstein-Barr virus-associated gastric carcinoma: a newly defined entity. J Clin Gastroenterol. 2012;46:262-71.

37. Koriyama C, Akiba S, Itoh T, Kijima Y, Sueyoshi K, Corvalan A, et al. Prognostic significance of Epstein-Barr virus involvement in gastric carcinoma in Japan. Int J Mol Med. 2002;10:635-9.

38. Kijima Y, Ishigami S, Hokita S, Koriyama C, Akiba S, Eizuru Y, et al. The comparison of the prognosis between Epstein-Barr virus (EBV)positive gastric carcinomas and EBV-negative ones. Cancer Lett. 2003; 200:33-40.

39. Sender R, Fuchs $\mathrm{S}$, Milo R. Are We Really Vastly Outnumbered? Revisiting the ratio of bacterial to host cells in humans. Cell. 2016;164:337-40.

40. Gill SR, Pop M, Deboy RT, Eckburg PB, Turnbaugh PJ, Samuel BS, et al. Metagenomic analysis of the human distal gut microbiome. Science. 2006; 312:1355-9.

41. Conlan S, Kong HH, Segre JA. Species-level analysis of DNA sequence data from the NIH Human Microbiome Project. PLoS One. 2012;7:e47075.

42. Macfarlane GT, Macfarlane S. Bacteria, colonic fermentation, and gastrointestinal health. J AOAC Int. 2012;95:50-60.

43. Thomas AM, Gleber-Netto FO, Fernandes GR, Amorim M, Barbosa LF, et al. Alcohol and tobacco consumption affects bacterial richness in oral cavity mucosa biofilms. BMC Microbiol. 2014;14:250.

44. Wang ZK, Yang YS. Upper gastrointestinal microbiota and digestive diseases. World J Gastroenterol. 2013;19:1541-50.
45. Stearns JC, Lynch MD, Senadheera DB, Tenenbaum HC, Goldberg MB, Cvitkovitch DG, et al. Bacterial biogeography of the human digestive tract. Sci Rep. 2011;1:170.

46. Aviles-Jimenez F, Vazquez-Jimenez F, Medrano-Guzman R, Mantilla A, Torres J. Stomach microbiota composition varies between patients with nonatrophic gastritis and patients with intestinal type of gastric cancer. Sci Rep. 2014;4:4202.

47. Tseng $\mathrm{CH}$, Lin JT, Ho HJ, Lai ZL, Wang CB, Tang SL, et al. Gastric microbiota and predicted gene functions are altered after subtotal gastrectomy in patients with gastric cancer. Sci Rep. 2016;6:20701.

48. Jo HJ, Kim J, Kim N, Park JH, Nam RH, Seok YJ, et al. Analysis of Gastric Microbiota by Pyrosequencing: Minor Role of Bacteria Other Than Helicobacter pylori in the Gastric Carcinogenesis. Helicobacter. 2016. In press.

49. Taborda AG, Prolla JC. Alimentary factors in the development of gastric intestinal metaplasia in functional dyspeptic patients. Arq Gastroenterol. 2012:49:208-13.

50. Park B, Shin A, Park SK, Ko KP, Ma SH, Lee EH, et al. Ecological study for refrigerator use, salt, vegetable, and fruit intakes, and gastric cancer. Cancer Causes Control. 2011;22:1497-502.

51. Correa P. Human gastric carcinogenesis: a multistep and multifactorial process-First American Cancer Society Award Lecture on Cancer Epidemiology and Prevention. Cancer Res. 1992;52:6735-40.

52. Lunet N, Lacerda-Vieira A, Barros H. Fruit and vegetables consumption and gastric cancer: a systematic review and meta-analysis of cohort studies. Nutr Cancer. 2005:53:1-10.

53. Chen ZM, Peto R, lona A, Guo Y, Chen YP, Bian Z, et al. China Kadoorie Biobank Collaborative Group. Emerging tobacco-related cancer risks in China: A nationwide, prospective study of 0.5 million adults. Cancer. 2015;17:3097-106.

54. Peleteiro B, Castro C, Morais S, Ferro A, Lunet N. Worldwide burden of gastric cancer attributable to tobacco smoking in 2012 and predictions for 2020. Dig Dis Sci. 2015;60:2470-6.

55. Tramacere I, Negri E, Pelucchi C, Bagnardi V, Rota M, Scotti L, et al. A metaanalysis on alcohol drinking and gastric cancer risk. Ann Oncol. 2012;23:28-36.

56. Global Burden of Disease Cancer Collaboration. The Global Burden of Cancer 2013. JAMA Oncol. 2015;1:505-27.

57. Tsugane S, de Souza JM, Costa ML, Mirra AP, Gotlied SL, Laurenti R, et al. Cancer incidence rates among Japanese immigrants in the city of São Paulo, Brazil, 1969-78. Cancer Causes Control. 1990;1:189-93.

58. Iwasaki M, Mameri CP, Hamada GS, Tsugane S. Cancer mortality among Japanese immigrants and their descendants in the state of São Paulo, Brazil, 1999-2001. Jpn J Clin Oncol. 2004;34:673-80.

59. Jemal A, Center MM, DeSantis C, Ward EM. Global patterns of cancer incidence and mortality rates and trends. Cancer Epidemiol Biomarkers Prev. 2010;19:1893-907.

60. Theuer CP, Kurosaki T, Ziogas A, Butler J, Anton-Culver H. Asian patients with gastric carcinoma in the United States exhibit unique clinical features and superior overall and cancer specific survival rates. Cancer. 2000:89:1883-92

61. Kim J, Sun CL, Mailey B, Prendergast C, Artinyan A, Bhatia S, et al. Race and ethnicity correlate with survival in patients with gastric adenocarcinoma. Ann Oncol. 2010;21:152-60.

62. Ohtsu A, Shah MA, Van Cutsem E, Rha SY, Sawaki A, Park SR, et al. Bevacizumab in combination with chemotherapy as first-line therapy in advanced gastric cancer: a randomized, double-blind, placebo-controlled phase III study. J Clin Oncol. 2011;29:3968-76.

63. Kim S, Chung JW, Jeong TD, et al. Searching for E-cadherin gene mutations in early onset diffuse gastric cancer and hereditary diffuse gastric cancer in Korean patients. Fam Cancer. 2013;12:503-7.

64. Kong X, Wang JL, Chen HM, Fang JY. Comparison of the clinicopathological characteristics of young and elderly patients with gastric carcinoma: a meta analysis. J Surg Oncol. 2012;106:346-52.

65. Corso G, Pedrazzani C, Pinheiro H, Fernandes E, Marrelli D, Rinnovati A, et al. E-cadherin genetic screening and clinico-pathologic characteristics of early onset gastric cancer. Eur J Cancer. 2011;47:631-9.

66. Corso G, Marrelli D, Pascale V, Vindigni C, Roviello F. Frequency of CDH1 germline mutations in gastric carcinoma coming from high- and low-risk areas: metanalysis and systematic review of the literature. BMC Cancer. 2012;12:8.

67. Kaurah P, MacMillan A, Boyd N, Senz J, De Luca A, Chun N, et al. Founder and recurrent $\mathrm{CDH} 1$ mutations in families with hereditary diffuse gastric cancer. JAMA. 2007;297:2360-2.

68. Brooks-Wilson A, Kaurah P, Suriano G, Leach S, Senz J, Grehan N, et al. Germline E-cadherin mutations in hereditary diffuse gastric cancer: 
assessment of 42 families and review of genetic screening criteria. J Med Genet. 2004;41:508-17.

69. Carneiro F, Oliveira C, Suriano G, Seruca R. Molecular pathology of familial gastric cancer, withan emphasis on hereditary diffuse gastric cancer. J Clin Pathol. 2008;61:25-30.

70. Yu QM, Wang XB, Luo J, Wang S, Fang XH, Yu JL, et al. CDH1 methylation in preoperative peritoneal washes is an independent prognostic factor for gastric cancer. J Surg Oncol. 2012;106:765-71.

71. Mastoraki A, Danias N, Arkadopoulos N, Sakorafas G, Vasiliou P, Smyrniotis V. Prophylactic total gastrectomy for hereditary diffuse gastric cancer. Review of the literature. Surg Oncol. 2011;20:e223-6.

72. da Silva FC, Oliveira LP, Santos EM, Nakagawa WT, Aguiar Jr S, Valentin MD, et al. Frequency of extracolonic tumors in Brazilian families with Lynch syndrome: analysis of a hereditary colorectal cancer institutional registry. Fam Cancer. 2010;9:563-70.

73. Ferreira FO, Ferreira CC, Rossi BM, Nakagawa WT, Aguilar S, Santos EM, et al. Frequency of extra-colonic tumors in HNPCC and familial colorectal cancer Brazilian families. Fam Cancer. 2004;3:41-7.

74. Simpson AJ, Caballero OL, Pena SD. Microsatellite instability as a tool for the classification of gastric cancer. Trends Mol Med. 2001;7:76-80.

75. Ferrasi AC, Pinheiro NA, Rabenhorst SH, Caballero OL, Rodrigues MA, de Carvalho F, et al. Helicobacter pylori and EBV in gastric carcinomas: Methylation status and microsatellite instability. World J Gastroenterol. 2010;16:312-9.

76. Holbrook JD, Parker JS, Gallagher KT, Halsey WS, Hughes AM, Weigman VJ, et al. Deep sequencing of gastric carcinoma reveals somatic mutations relevant to personalized medicine. J Transl Med. 2011;9:119.

77. da Silva MC, Zuccherato LW, Lucena FC, Soares-Souza GB, Vieira ZM, Pena SD, et al. Extensive admixture in Brazilian sickle cell patients: implications for the mapping of genetic modifiers. Blood. 2011;118:4493-5.

78. Cunningham D, Allum WH, Stenning SP, Thompson JN, Van de Velde CJ Nicolson $\mathrm{M}$, et al. Perioperative chemotherapy versus surgery alone for resectable gastroesophageal cancer. New Engl J Med. 2006;355:11-20.

79. Ychou M, Boige V, Pignon JP, Conroy T, Bouche O, Lebreton G, et al. Perioperative chemotherapy compared with surgery alone for resectable gastroesophageal adenocarcinoma: an FNCLCC and FFCD multicenter phase III trial. J Clin Oncol. 2011;29:1715-21.

80. Mansour JC, Tang L, Shah M, Bentrem D, Klimstra DS, Gonen M, et al. Does graded histologic response after neoadjuvant chemotherapy predict survival for completely resected gastric cancer? Ann Surg Oncol. 2007;14:3412-8.

81. Bang YJ, Van Cutsem E, Feyereislova A, Chung HC, Shen L, Sawaki A, et al. Trastuzumab in combination with chemotherapy versus chemotherapy alone for treatment of HER2-positive advanced gastric or gastrooesophageal junction cancer (ToGA): a phase 3, open-label, randomised controlled trial. Lancet. 2010;376:687-97.

82. Begnami MD, Fukuda E, Fregnani $J H$, Nonogaki S, Montagnini AL, da Costa Jr WL, et al. Prognostic implications of altered human epidermal growth factor receptors (HERs) in gastric carcinomas: HER2 and HER3 are predictors of poor outcome. J Clin Oncol. 2011;29:3030-6.

83. Fuchs CS, Tomasek J, Yong CJ, Dumitru F, Passalacqua R, Goswami C, et al, Ramucirumab monotherapy for previously treated advanced gastric or gastrooesophageal junction adenocarcinoma (REGARD): an international, randomised, multicentre, placebo-controlled, phase 3 trial. Lancet. 2014;383:31-9.

84. Wilke H, Muro K, Van Cutsem E, Oh SC, Bodoky G, Shimada Y, et al. Ramucirumab plus paclitaxel versus placebo plus paclitaxel in patients with previously treated advanced gastric or gastro-oesophageal junction adenocarcinoma (RAINBOW): a double-blind, randomised phase 3 trial. Lancet Oncol. 2014;15:1224-35.

85. Li J, Qin S, Xu J, Xiong J, Wu C, Bai Y, et al. Randomized, Double-Blind, Placebo-Controlled Phase III Trial of Apatinib in Patients With Chemotherapy-Refractory Advanced or Metastatic Adenocarcinoma of the Stomach or Gastroesophageal Junction. J Clin Oncol. 2016;34:1448-54.

86. Zhang L, Qiu M, Jin Y, Ji J, Li B, Wang X, et al. Programmed cell death ligand 1 (PD-L1) expression on gastric cancer and its relationship with clinicopathologic factors. Int J Clin Exp Pathol. 2015:8:11084-91.

87. Raufi AG, Klempner SJ. Immunotherapy for advanced gastric and esophageal cancer: preclinical rationale and ongoing clinical investigations. J Gastrointest Oncol. 2015;6:561-9.

88. Alix-Panabières $C$, Pantel K. Challenges in circulating tumour cell research. Nature Rev Cancer. 2014;14:623-31.

89. Mukai M. Occult neoplastic cells and malignant micro-aggregates in lymph node sinuses: review and hypothesis. Oncol Rep. 2005;14:173-5.
90. Aceto N, Bardia A, Miyamoto DT, Donaldson MC, Wittner BS, Spencer JA et al. Circulating tumor cell clusters are oligoclonal precursors of breast cancer metastasis. Cell. 2014;158:1110-22.

91. Paterlini-Brechot $P$, Benali NL. Circulating tumor cells (CTC) detection: clinical impact and future directions. Cancer Lett. 2007;253:180-204.

92. Hiraiwa K, Takeuchi H, Hasegawa H, Saikawa Y, Suda K, Ando T, et al. Clinical significance of circulating tumor cells in blood from patients with gastrointestinal cancers. Ann Surg Oncol. 2008;15:3092-100.

93. Matsusaka S, Chin K, Ogura M, Suenaga M, Shinozaki E, Mishima Y, et al. Circulating tumor cells as a surrogate marker for determining response to chemotherapy in patients with advanced gastric cancer. Cancer Sci. 2010;101:1067-71.

94. Zhang Z, Dai Z, Yin X, Li S, Li S, Ge H. Meta-analysis shows that circulating tumor cells including circulating microRNAs are useful to predict the survival of patients with gastric cancer. BMC Cancer. 2014;14:773.

95. Huang X, Gao P, Sun J, Chen X, Song Y, Zhao J, et al. Clinicopathological and prognostic significance of circulating tumor cells in patients with gastric cancer: A meta-analysis. Int J Cancer. 2015;136:21-33.

96. Raposo G, Stoorvogel W. Extracellular vesicles: exosomes, microvesicles, and friends. J Cell Biol. 2013;200:373-83.

97. Lee TH, D’Asti E, Magnus N, Al-Nedawi K, Meehan B, Rak J. Microvesicles as mediators of intercellular communication in cancer-the emerging science of cellular "debris". Semin Immunopathol. 2011:33:455-67.

98. Peinado H, Aleckovic A, Lavotshkin S, Matei I, Costa-Silva B, Moreno-Bueno $\mathrm{G}$, et al. Melanoma exosomes educate bone marrow progenitor cells toward a pro-metastatic phenotype through MET. Nat Med. 2012;18:883-91.

99. Hood JL, San RS, Wickline SA. Exosomes released by melanoma cells prepare sentinel lymph nodes for tumor metastasis. Cancer Res. 2011;71:3792-801.

100. Roberson CD, Atay S, Gercel-Taylor C, Taylor DD. Tumor-derived exosomes as mediators of disease and potential diagnostic biomarkers. Cancer Biomark. 2010-2011;8:281-91

101. Skog J, Wurdinger T, Rijn S, Meijer D, Gainche L, Sena-Esteves M, et al. Glioblastoma microvesicles transport RNA and proteins that promote tumour growth and provide diagnostic biomarkers. Nat Cell Biol. 2008;10:1470-6.

102. Amorim M, Fernandes G, Oliveira P, Martins-de-Souza D, Dias-Neto E, Nunes DN. The overexpression of a single oncogene (ERBB2/HER2) alters the proteomic landscape of extracellular vesicles. Proteomics. 2014;14:1472-9.

103. Tajiri R, Ooi A, Fujimura T, Dobashi $Y$, Oyama T, Nakamura $R$, et al. Intratumoral heterogeneous amplification of ERBB2 and subclonal genetic diversity in gastric cancers revealed by multiple ligation-dependent probe amplification and fluorescence in situ hybridization. Hum Pathol. 2014;45:725-34.

104. Baran J, Baj-Krzyworzeka M, Weglarczyk K, Szatanek R, Zembala M, Barbasz J, et al. Circulating tumour-derived microvesicles in plasma of gastric cancer patients. Cancer Immunol Immunother. 2010;59:841-50.

105. Qu JL, Zhao MF, Qu XJ, Teng YE, Zhang Y, Hou KZ, et al. Gastric cancer exosomes promote tumour cell proliferation through PI3K/Akt and MAPK ERK activation. Dig Liver Dis. 2009:41:875-80.

106. Li Q, Shao Y, Zhang X, Zheng T, Miao M, Qin L, et al. Plasma long noncoding RNA protected by exosomes as a potential stable biomarker for gastric cancer. Tumour Biol. 2015;36:2007-12.

\section{Submit your next manuscript to BioMed Central and we will help you at every step:}

- We accept pre-submission inquiries

- Our selector tool helps you to find the most relevant journal

- We provide round the clock customer support

- Convenient online submission

- Thorough peer review

- Inclusion in PubMed and all major indexing services

- Maximum visibility for your research

Submit your manuscript at www.biomedcentral.com/submit
) Biomed Central 